\title{
VELOCITY PROFILE VISUALIZATION OF WATER NATURAL PERCOLATION IN A POROUS MEDIUM
}

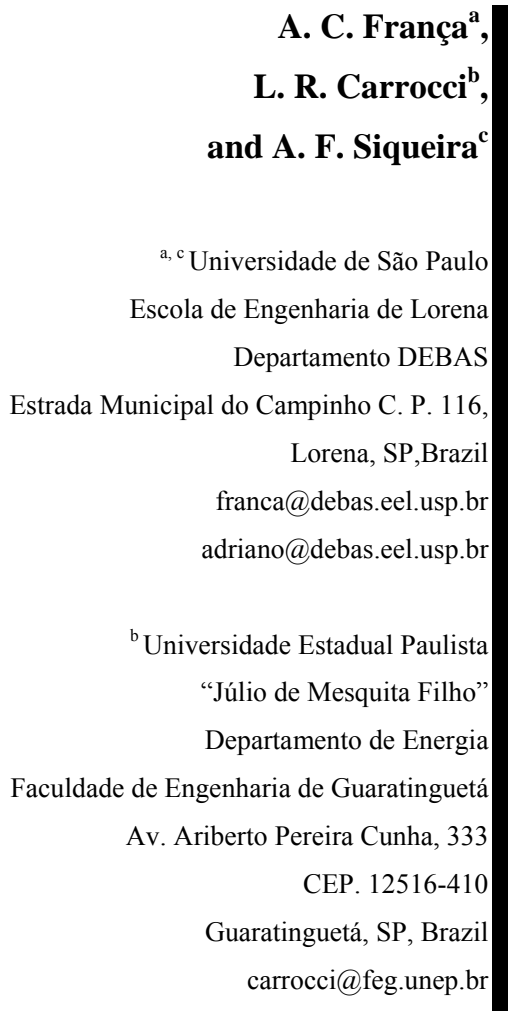

ABSTRACT

This paper aims to show the profile and the behavior of the velocity of the water flow through a porous medium composed of clay and sand aggregated by burning in an oil furnace. The work models mathematics based on the Navier-Stokes differential equation, which represents the behavior of the water velocity flow in porous medium taking into account parameters of a low velocity laminar flow, increased load loss value and Number of Reynolds $>1$. Physical phenomena such as porosity, permeability, particles arrangement, radius and wet perimeter are considered in the equation. The study shows the three-dimensional profile of the water percolation velocity which, originated from the capillary phenomenon, causes a sum of the tensions of increased values able to produce cracks in the medium structure. And, differently from filtration phenomenon, which overcomes the capillarity of the medium by the gravitational force or by efforts applied aiming to increase the flow velocity, the natural percolation opposes to the gravity and to the surrounding pressure moving slowly, reaching the flow at 30 and 40 centimeters depending on the permeability of the porous medium.

Keywords: porosity, percolation, porous medium, hygroscopy

\section{NOMENCLATURE}

A section, area, $\mathrm{mm} 2$

Av area of emptiness, $\mathrm{mm} 2$

$\mathrm{d}, \mathrm{Dp} \quad$ medium diameter of the particle, $\mathrm{mm}$

e width of the fissure, $\mathrm{mm}$

$\mathrm{F}_{\mathrm{Re}}$ coefficient of correction of the Reynolds

$\mathrm{h}, \mathrm{h}_{\mathrm{h}}$ length, $\mathrm{cm}$

i load loss for unit of length, atm/cm

$\mathrm{J}$ relationship isometric

$\mathrm{K}$ coefficient of permeability, $\mathrm{mm} / \mathrm{s}$

$\mathrm{L}, \mathrm{l}$ length, $\mathrm{mm}$

$\mathrm{P}, \mathrm{P}_{0}$, pressure, $\mathrm{kgf} / \mathrm{mm} 2$

$\mathrm{Q}, \mathrm{q}$ out flow, $\mathrm{ml} / \mathrm{s}$ or $\mathrm{cm} 3 / \mathrm{s}$

Re, Re' Number of Reynolds

$\mathrm{t}$ time, $\mathrm{s}$

Ts superficial tension, $\mathrm{mg} / \mathrm{mm} 2$

$\mathrm{U}_{0} \quad$ speed initial $\mathrm{mm} / \mathrm{s}$

Vmed speed medium $\mathrm{mm} / \mathrm{s}$

$\mathrm{V}$ speed no dimensional

$\mathrm{Vc}, \mathrm{v} \quad$ speed critical $\mathrm{mm} / \mathrm{s}$

$\mathrm{W}_{\text {med }}$ dimensional medium speed, $\mathrm{cm} / \mathrm{s}$

$\mathrm{x}, \mathrm{y}, \mathrm{z}$ ortogonal components

$\mathrm{u}, \mathrm{v}, \mathrm{w}$ ortogonal components

$\mathrm{x} 1, \mathrm{y} 1$ no dimensional components

z1 no dimensional components

\section{Greek symbols}

$\alpha$ angle, degrees

$\mu \quad$ dynamic viscosity, $\mathrm{kg} / \mathrm{mm} . \mathrm{s}$

$\rho$ specific mass

$\psi$ esfericidade

$\sigma$ tension of deformation, $\mathrm{kgf} / \mathrm{mm} 2$

$\Delta \mathrm{L}$ deformation $\mathrm{mm}$

$\gamma_{\mathrm{a}}$ dilation coefficient, ${ }^{\circ} \mathrm{C}^{-1}$

\section{Subscripts}

$\perp$ perpendicular

| | parallel

$\mathrm{T}$ traversal

L longitudinal

$\mathrm{H}$ horizon

\section{INTRODUCTION}

The identification of cracks in brick masonry is quite common, not only after a certain period of postbuilding time but also, sometimes, during the building. These cracks or structural deformations are due to several factors of technical order. One of them is related to the moistness absorbed by the elements of the wall (brick and mortar). Such moistness can be the result of the environment conditions (dank day), rain, soil and even the excess of water in the laid mortar. In contact with the wall porous elements, 
brick and mortar, the water will facilitate the capillary percolation, giving birth to remarkable internal efforts, which will cause structural dislocation. These dislocations are usually different for the brick and for the mortar, so causing the cracks. The phenomena that cause the deformations were studied in a research by FRANÇA (2000), analyzed and quantified in laboratory, validating the hypothesis that the sum of the capillary efforts caused by the dislocation of a fluid in a porous element can reach high values up to a point that causes dislocations and consequently cracks in the structure. Therefore, the dislocation of the fluid through the channels existing among the particles of the porous element, processed in form of a dislocating front of fluid, named velocity of percolation, needed to be visualized and mathematically treated.

The objective of this work is to trace the profile of the dislocation and give the velocity of percolation a mathematical modeling based on the general equation of Navier-Stokes.

It was necessary to search for knowledge of micro world of the labyrinths formed by pores among sand, clay and cement particles. It became indispensable to measure, in an indirect way, the size of the pores and its relation with the size of the particles. It was also necessary to relate elements of an extremely low velocity laminar fluid flowage, with Number of Reynolds smaller than one, and relate among them parameters such as wet perimeter, hydraulic radius, porosity, circularity and physical arrangement among the particles, in such a way to make possible a vision of the phenomena by analogy and comparison with porous mediums of previously known dimensions.

Altogether, the studies of percolation in porous elements are linked to the phenomena of filtration and to the actions that may optimize the process. Differently, this research was focused on natural percolation with no external interferences. With only the capillary efforts acting, and having as reaction the losses of natural charge to a laminar flowage, the result is an environmental pressure and the gravitational effort.

The characteristics of the porous element and the types of water found in the porous structure are herein presented. Aspects of the flowage in ceramic porous elements of brick and mortar masonry are broached. It also presents the basis of the proposal of modeling to perform the estimates for the values of efforts and velocity. It shows the values obtained in form of tables and graphs and details the methodology and procedures utilized to choose the bodies of proof, measurements and description of the instruments and equipments utilized. Conclusions are presented on what was developed and observed, together with some suggestions on precautions to be taken concerning the masonry elements in order to prevent the inconvenient cracks and the troublesome visual effects, besides suggestions for works to come.

\section{THEORETICAL DEVELOPMENT}

Due to the fact that it is transitory, the flow stops when it reaches the points of pressure equal to the capillary pressure. Therefore, from the NavierStokes in its differential form of the amount of movement, Eq. (1), with analysis of amount of terms, it is possible to have the governing equation in the vertical and preferential directions of percolation, as it follows:

$$
\frac{\partial V}{\partial t}+\frac{V \partial V}{\partial z}=-\frac{1}{\rho} \frac{\partial P}{\partial z}-\frac{\mu V}{\rho K}
$$

With the initial and contour conditions:

For $\mathrm{z}=0$

$$
\begin{array}{cccc}
\mathrm{t}=0 \rightarrow & \mathrm{V}=0 \quad \text { e } & \mathrm{P}=\mathrm{P}_{0}=\mathrm{h}^{\prime}+\mathrm{h}^{\prime}{ }_{\text {in } 30 \mathrm{~cm}} \\
\mathrm{t}>0 \rightarrow & \mathrm{z}=0 \\
& \mathrm{z}=\mathrm{h} & \rightarrow & \mathrm{V}=\mathrm{Q} / \mathrm{A} \\
& \mathrm{V}=0
\end{array}
$$

where " $\mathrm{z}$ " is the flow vertical direction, " $\mathrm{t}$ " is the time, "P" shows the loss of charge, " $\mathrm{P}_{0}$ " indicates the static pressure, " $h$ " is the initial height and " $h_{\text {in } 30}$ $\mathrm{cm}$ " represents the height experimentally measured in França (2000), reached by the water, by percolation, in masonry wall.

Applying the following adimensionalization for the equation of Navier-Stokes:

$$
\begin{aligned}
& V^{\prime}=\frac{V}{V_{0}} ; Z^{\prime}=\frac{Z}{h} ; P^{\prime}=\frac{P}{\rho V_{0}^{2}} t^{\prime}=\frac{t}{h / V_{0}}=\frac{t \cdot V_{0}}{h} \\
& V=V^{\prime} V_{0} ; Z=Z^{\prime} h ; P=P^{\prime} \rho V_{0}^{2} ; t=\left(\frac{h}{V_{0}}\right) t^{\prime}
\end{aligned}
$$

and substituting in (1), we find:

$$
\begin{aligned}
& \frac{V_{0}}{h / V_{0}} \frac{d V^{\prime}}{d t^{\prime}}+\frac{V_{0} V^{\prime} V_{0}}{h} \frac{d V^{\prime}}{d z^{\prime}}=\frac{-1}{\rho} \frac{\rho V_{0}^{2}}{h} \frac{d P^{\prime}}{d z^{\prime}}-\frac{\mu}{\rho K} V_{0} V^{\prime} \Rightarrow \\
& \Rightarrow \frac{V_{0}^{2}}{h} \frac{d V^{\prime}}{d t^{\prime}}+\frac{V_{0}^{2} V^{\prime}}{h} \frac{d V^{\prime}}{d z^{\prime}}=\frac{-V_{0}^{2}}{h} \frac{d P^{\prime}}{d z^{\prime}}-\frac{\mu V_{0}}{\rho K} V^{\prime} \\
& \frac{d V^{\prime}}{d t^{\prime}}+\frac{V^{\prime} d V^{\prime}}{d z^{\prime}}=\frac{-d P^{\prime}}{d z^{\prime}}-\frac{\mu \cdot h}{\rho K V_{0}} V^{\prime}
\end{aligned}
$$

where: $\frac{d P^{\prime}}{d z^{\prime}}$ is the factor of pressure, $\frac{\mu h}{\rho K V_{0}}$ is the

porosity and $\frac{d V^{\prime}}{d t^{\prime}}+V^{\prime} \frac{d V^{\prime}}{d z^{\prime}}=\mathrm{B}$

where " $\mathrm{B}$ " is a factor composed by the variation of loss of charge, that is, a combination of static pressure and resistance to the dislocation of the fluid 
by the factor of porosity, and "P" is the NavierStokes equation adimensionalized term of pressure.

$$
\begin{aligned}
& \mathrm{P}^{\prime}=\frac{P}{P_{0}}=\frac{P}{\rho V_{0}^{2}}=\frac{\rho g h}{\rho V_{0}^{2}}=\frac{g h}{V_{0}^{2}}=\frac{g f \Delta L V_{0}^{2} V^{\prime 2}}{V_{0}^{2} D_{h} 2 g}=\frac{f \Delta L}{2 D_{h}}\left(V^{\prime}\right)^{2} \Rightarrow \\
& \Rightarrow \frac{\partial V^{\prime}}{\partial z^{\prime}}=\frac{f \Delta L}{D_{h}} \cdot V^{\prime} \frac{\partial V^{\prime}}{\partial z^{\prime}}
\end{aligned}
$$

where " $\mathrm{f}$ " is a factor of attrition considered constant when a flow in a laminar regimen in a porous medium composed of homogeneous spheres, in which the number of Reynolds is very small, i.e., Rey $<<10$, Papanastasious (1994). Reassembling the equation (2) we have:

$$
\frac{\partial V^{\prime}}{\partial t^{\prime}}+\frac{V^{\prime} \partial V^{\prime}}{\partial z^{\prime}}=-\left[\frac{f \Delta L}{D_{h}} V^{\prime} \frac{\partial V^{\prime}}{\partial z^{\prime}}+\frac{\mu}{\rho K V_{0}} \frac{f \Delta L V_{0}^{2}}{D_{h} 2 g}\left(V^{\prime}\right)^{3}\right]
$$

being "V" in the porous medium a very small superficial velocity and " $\mathrm{f}$ " constant,

$$
\begin{aligned}
& \frac{\partial V^{\prime}}{\partial t^{\prime}}+\frac{V^{\prime} \partial V^{\prime}}{\partial z^{\prime}}=-\frac{f \Delta L}{D_{h}} V^{\prime} \frac{\partial V^{\prime}}{\partial z^{\prime}} \quad \Rightarrow \\
& \frac{\partial V^{\prime}}{\partial t^{\prime}}+\left(1+\frac{\rho \Delta L}{D_{h}}\right) \cdot V^{\prime} \frac{\partial V^{\prime}}{\partial z^{\prime}}=0
\end{aligned}
$$

For analytical solution through separation of variables the notation " " will no longer be used for the $z^{\prime}$ and 't' variables in the following calculations, aiming to simplify the deduction and avoid mistakes with the traditional symbology used for the derivates.

$\mathrm{V}^{\prime}=\mathrm{H}(\mathrm{t}) \cdot \mathrm{G}(\mathrm{z})$

thus,

$H^{\prime}(t) \cdot G(z)+\left(1+\frac{f \Delta L}{D_{h}}\right) \cdot H(t) \cdot G(z) \cdot H(t) \cdot G^{\prime}(z)=0 \quad \Rightarrow$ the analytical two-dimensional solution is:

$\Rightarrow \frac{H^{\prime}(t)}{H^{2}(t)}+\left(1+\frac{f \Delta L}{D_{h}}\right) \cdot G^{\prime}(z)=0$

making:

$$
\begin{aligned}
& \frac{H^{\prime}(t)}{H^{2}(t)}=-\lambda \Rightarrow H(t)=\frac{1}{\lambda t+C_{2}} \\
& \mathrm{G}^{\prime}(\mathrm{z})=-\lambda\left(\frac{D_{h}}{1+f \Delta L}\right) \Rightarrow \mathrm{G}(\mathrm{z})=C_{1}-\frac{\lambda D_{h}}{(1+f \Delta L)} \cdot z \\
& \mathrm{~V}^{\prime}(\mathrm{z}, \mathrm{t})=\frac{C_{1}-\frac{\lambda D_{h}}{(1+f \Delta L)} \cdot z}{\lambda t+C_{2}}
\end{aligned}
$$

Conditions of Contour for $\mathrm{V}^{\prime}(\mathrm{z}, \mathrm{t})$ adimensionalized:

$$
\begin{aligned}
& \mathrm{V}^{\prime}(\mathrm{z}, 0)=1 \\
& \mathrm{~V}^{\prime}(1, \mathrm{t})=0 \\
& C_{1}=\frac{\lambda D_{h}}{(1+f \Delta L)} \\
& C_{2}=\frac{\lambda D_{h}}{(1+f \Delta L)} \cdot(1-z)
\end{aligned}
$$

thus, $\mathrm{V}^{\prime}(\mathrm{z}, \mathrm{t})=\frac{\frac{\lambda D_{h} \cdot(1-z)}{(1+f \Delta L)}}{\lambda t+\frac{\lambda D_{h} \cdot(1-z)}{(1+f \Delta L)}}$

that is the adimensionalized equation, which represents the velocity of percolation.

In order to solve the Eq. (13) it must be adimensionalized by multiplying by $\mathrm{V}_{0}$ and adopting the value of the fluid friction factor with the "f" porous medium of Papanastasious (1994) with which, through the equation of Ergun, it is verified that the losses by attrition decrease with the addition of the porosity $\varphi$ and with the size of the particle $D_{p}$. $f$ is a factor for porous mediums, empirically quantified by some authors, as shown by the equations:

1) Ergun
$f=1,75 u_{s}^{2}\left(\frac{\Delta L}{D p}\right)\left(\frac{1-\varphi}{\varphi^{3}}\right)+150 u_{s}\left(\frac{\Delta l}{D_{p}^{2}}\right)\left(\frac{1-\varphi}{\varphi^{3}}\right)\left(\frac{\mu}{\rho}\right)$

2) Blake - Kozeny (laminar flow)

$$
f=150 u_{s}\left(\frac{\Delta l}{D_{p}^{2}}\right)\left(\frac{1-\varphi}{\varphi^{3}}\right)\left(\frac{\mu}{\rho}\right) \quad \text { para Rey }<10
$$

3) Burke - Plumbes (turbulent flow)

$$
f=175 u_{s}^{2}\left(\frac{\Delta L}{D_{p}^{2}}\right)\left(\frac{1-\varphi}{\varphi^{3}}\right) \text { para Rey }>1000
$$

Ergun presents the Eq. (14) as the sum of two terms. The first term is the Eq. (15) of Blake Kozeny for laminar flow, for number of Reynolds smaller than 10, which is the case studied, flow in porous mediums at low velocity. The second term, Eq. (16) of Burke - Plumbes, for turbulent flows is not applicable to this case.

It is noticed in Fig. 1 that an extrapolation of the curve formed by the Equation of Blake - Kozen comes to a straight line of $45^{\circ}$ inclination when the value of the number of Reynolds tends to zero, giving $f$ the value of 970 which will be utilized in the resolution of the Eq. (13). This value was adopted here considering that the Eq. (15) of Blake-Kozeny presents continuity and linear behavior for Reynolds 
$<10$, according to the traced line in the extrapolation of Fig. 1.

The analysis of the porous mediums depends sensibly on the pores size and the accuracy of the measurement of the porosity of the mediums as well as the loss of charge to which the fluid is submitted. The value $f=970$ was adopted, by extrapolation in Fig. 1, because it was not found in the literature and in electronic sites available any subject related to the factor of attrition for flows whose velocity corresponded to a number of Reynolds tending to zero, that is, for a laminar flow with very low velocity and with no external efforts influence.

Considering that in laminar flows the functions are linear, and that a throrough observation in Fig. 1 shows that the points in the upper part of the graph tend to an alignment, with very little dispersion close to a traced medium line under the influence of the term of Blake - Kozeny, Eq. (15) is visible and the condition of linearity for a laminar flow at extremely low velocity is determining.

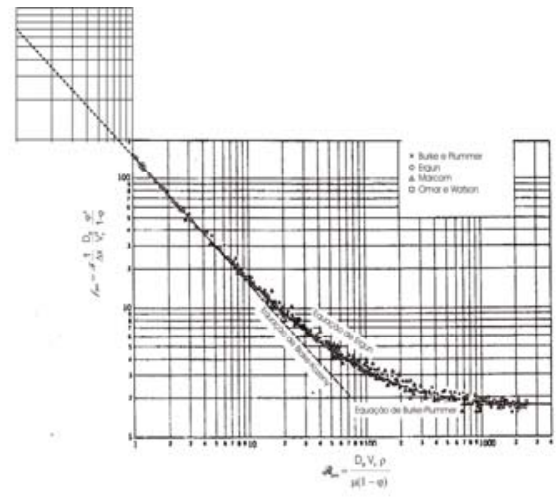

Figure 1 - Extrapolation of the curve of Papanastasious for the obtainment of the factor $f$ for a number of Reynolds $<<1$, laminar regimen.

The linearity and the small dispersion of the points in the interval $1<$ Rey $<10$ provided us security to adopt the extrapolation. Values of the hydraulic diameter " $\mathrm{D}_{\mathrm{h}}$ " $=1$ are also adopted, which consider that the porous medium is composed of same diameter totally wet spheres and the porosity intrinsic to it through the number of Reynolds:

$$
R h_{\text {mpe }}=\frac{\varphi D p}{6(1-\varphi)}
$$

where " $\mathrm{Rh}_{\text {mpe" }}$ is the hydraulic radius of the porous medium composed of spherical particles, $\varphi$ is the porosity of medium and "Dp" the diameter of the spherical particle.

In the adimensionalized equation, for the value of the area where the flow experimentally measured $\mathrm{Q}=0,01475\left(\mathrm{~cm}^{3} / \mathrm{s}\right)$ flows off, $\mathrm{A}=1\left(\mathrm{~cm}^{2}\right)$ was adopted and for this height toward $\mathrm{z}=30(\mathrm{~cm})$,
Caputo (1978) values that were also obtained experimentally in França (2000).

\section{RESULTS AND DISCUSSIONS}

With these values, it was possible to trace Figure 2 which shows the behavior of the velocity of the front of percolation equation $\mathrm{V}(\mathrm{z}, \mathrm{t})$, the dislocation front behavior of the percolation along with an imaginary porous medium, composed of spheres of same diameter and arranged in cubic shape.

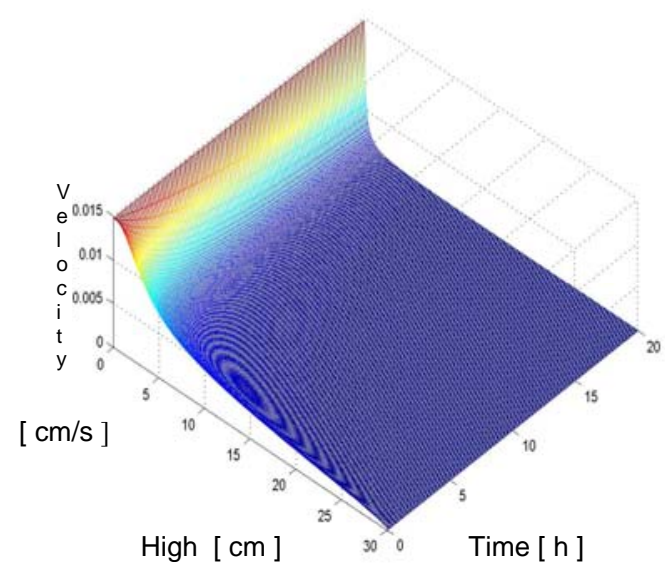

Figure 2 - Three-dimensional view of the behavior of the fluid percolation velocity in the porous medium composed of equivalent spheres (Only illustrative colors were utilized).

It can be noticed that in the initial time equal to zero, being understood that there is not dislocation of the fluid in the porous medium yet, $t$ must be adopted an initial flow, a movement of the fluid reaching the medium independently of the factor of capillarity which then starts inducing the phenomenon of percolation when the fluid reaches the medium. As the fluid penetrates the porous medium, under the effect of the capillarity, the loss of charge starts interfering directly in the dislocation of the initial flow, leading to a tendency of nullification around the instant 20, as it can be seen in the upper point of the figure.

Once started the dislocation, the percolation occurs up to height 30 , lower point of the figure, when the movement practically stops, confirming the experimental results obtained. At that point there will no longer be dislocation of the fluid, due to the effort generated by the capillarity, if they equal in module to the losses of charge generated by the atmospheric pressure, by the gravity and by the losses from the trajectory (cohesion, superficial rugosity, fluid viscosity and dimensional variations of channel). The advantage of the adimensionalized behavior analysis of the equation of the velocity is linked to the possibility of visualization of the percolation independently of values initially adopted as contour 
conditions, that is, from the instant the fluid reaches the medium, If there is not any external efforts, the dislocation will occur through the capillary effect and while this capillary effect exists and is superior to the effect of the losses of natural charges of the medium. The $\mathrm{z}, \mathrm{t}$, height and time variables become visibly dependent on the pores dimensions. Both $\mathrm{z}$ and $\mathrm{t}$ nullify each other for a non- porous medium (pores dimensions tending to zero) and nullify each other again at the extremes of the mediums composed of macro pores when the dimensions of the channels become too big nullifying the capillary effect.

An analysis of "h", the loss of charge by percolation, is also interesting to confirm the phenomenon due to the natural restrictions to the flow in the porous medium. The loss of charge, a loss of pressure, will improve up to the point it reaches the capillary pressure, when the flow stops. Considering " $h$ " as the factor of loss of charge studied and suggested by Papanastasious(1994), Eq. (17), we have:

$$
h=f \frac{\Delta L}{D_{h}} \cdot \frac{V^{2}}{2 g}=f \frac{\Delta L\left(V_{0}\right)^{2}}{2 g D_{h}}\left(V^{\prime}\right)^{2}
$$

\section{FACTOR “H” DIMENSIONAL ANALYSIS}

a) From the equation (18) it can be written:

$\left.\mathrm{h}]=[\mathrm{f}]\left[\Delta \mathrm{L} / \mathrm{D}_{\mathrm{h}}\right] \cdot\left[\mathrm{vo}_{\mathrm{o}}{ }^{2} / 2 \mathrm{~g}\right]=[\mathrm{L} / \mathrm{L}] \cdot \mathrm{L}^{2} \mathrm{~T}^{-2} / \mathrm{LT}^{-2}\right] \Rightarrow[\mathrm{h}]=[\mathrm{L}]$

b) As differences of pressure

$$
\begin{aligned}
& {[\mathrm{h}]=[\Delta \mathrm{P}]=[\rho \mathrm{gz}] \Rightarrow[\mathrm{h}]=\left[\frac{M L T^{-2}}{L^{2}}\right]=\left[\mathrm{ML}^{-3} \mathrm{LT}^{-2} \mathrm{~L}\right]} \\
& \Rightarrow[\mathrm{h}]=\left[\frac{M L T^{-2}}{L^{2}}\right]=\left[\frac{M}{L^{3}} \frac{L}{T^{2}}\right] .[\mathrm{L}] \Rightarrow[\mathrm{h}]=[\mathrm{L}](19)
\end{aligned}
$$

which is the height to be reached by the fluid through percolation in the porous medium, a factor dependent on the sum of the losses of charges imposed by the trajectory made by the fluid in the porous medium and of the surrounding pressure.

\section{REFERENCES}

Caputo, H. P., 1987, Mecânica dos Sólidos e Suas Aplicações. 5. Ed. Rio de Janeiro: L.T.C., 242p. (in Portuguese)

França, A. C., 2000, Escoamento em Meios Porosos: Uma Análise Teórica e Experimental dos Efeitos dos Esforços Capilares Provocados por Percolação de Água em Elementos de Alvenaria, Dissertação (mestrado em Engenharia Mecânica Transmissão e Conversão de Energia) - Faculdade de Engenharia do Campus de Guaratinguetá, UNESP, Guaratinguetá. (in Portuguese)
Papanastasious, T. C. 1994. Applied Fluid Mechanics, N. Jersey: Printece Hall, 532 p. SBN 013-060799-1.

Received: July 12, 2008

Revised: August 12, 2008

Accepted: September 12, 2008 